\title{
AN INTEGRATED INTERNATIONAL APPROACH TO ARCTIC OCEAN OBSERVATIONS FOR SOCIETY (A LEGACY OF THE INTERNATIONAL POLAR YEAR)
}

\author{
John Calder ${ }^{(1)}$, Andrey Proshutinsky ${ }^{(2)}$, Eddy Carmack ${ }^{(3)}$, Igor Ashik ${ }^{(4)}$, Harald Loeng ${ }^{(5)}$, Jeff Key ${ }^{(6)}$, \\ Moll McCammon ${ }^{(7)}$, Humfrey Melling ${ }^{(3)}$, Donald Perovich ${ }^{(8)}$, Hajo Eicken ${ }^{(9)}$, Mark Johnson ${ }^{(10)}$, \\ Ignatius Rigor ${ }^{(11)}$ \\ ${ }^{(1)}$ NOAA (National Oceanic and Atmospheric Administration) Climate Program Office R/CPO, Arctic Research \\ Program, 1100 Wayne Ave., Silver Spring, Maryland 20910-5603 USA, Email: John.Calder@ noaa.gov \\ ${ }^{(2)}$ Woods Hole Oceanographic Institution, MS\#29 360 Woods Hole Road Woods Hole MA 02543, USA, \\ Email: aproshutinsky@whoi.edu \\ ${ }^{(3)}$ Institute of Ocean Sciences, 9860 West Saanich Road, PO Box 6000, Sidney V8L 4B2, B.C., Canada, \\ Email: carmacke@pac.dfo-mpo.gc.ca; MellingH@pac.dfo-mpo.gc.ca \\ ${ }^{(4)}$ Arctic and Antarctic Research Institute, 38 Bering Street, St. Petersburg, 199397, Russia \\ Email: ashik@aari.nw.ru \\ ${ }^{(5)}$ Institute of Marine Research, P.O. Box 1870 Nordnes NO-5817 Bergen Norway, \\ Email: harald.loeng@imr.no \\ ${ }^{(6)}$ National Oceanic and Atmospheric Administration, 1225 W. Dayton St. Madison, WI 53706 USA, \\ Email: jkey@ssec.wisc.edu \\ (7)Alaska Ocean Observing System, 1007 W 3rd Ave \# 100, Anchorage, AK 99501-1936 USA, \\ Email: mccammon@aoos.org \\ ${ }^{(8)}$ Cold Regions Research and Engineering Laboratory, 603-646-4255 Investigator 72 Lyme Rd. Hanover, \\ New Hampshire 03755-1290 USA, Email: donald.k.perovich@erdc.usace.army.mil \\ ${ }^{(9)}$ University of Alaska Fairbanks, 907 Yukon Dr, P.O. Box 757320, Fairbanks, AK 99775-7320, USA, \\ Email: hajo.eicken@gi.alaska.edu \\ ${ }^{(10)}$ University of Alaska Fairbanks, 111 O'Neill, P.O. Box 757220, Fairbanks, AK 99775-7220, USA, \\ Email: johnson@ims.uaf.edu \\ ${ }^{(10)}$ University of Washington, 1013 NE 40 ${ }^{\text {th }}$, Seattle, WA 98105, USA, \\ Email:ignatius@apl.washington.edu
}

\section{INTRODUCTION, SCOPE, PURPOSE}

This White Paper takes a broad pan-Arctic approach to describe a plan for sustained ocean observations in the Arctic region directed to providing societal benefits, focusing on fulfilling the ocean component of the Global Climate Observing System in the Arctic region, while serving other needs as well. It will describe the most important in situ platforms and address associated modeling and analysis activities. The paper starts with a description of the in situ Arctic Observing Network/System required for ocean physics, ocean biology and biogeochemistry, sea ice, and the atmosphere over the Arctic Ocean. We discuss remote sensing techniques for the Arctic, and then discuss issues regarding data management, organization and Exclusive Economic Zones.

\section{SCIENTIFIC AND SOCIETAL BASES FOR OCEAN OBSERVATIONS IN THE ARCTIC REGION}

Monitoring of the ocean provides sets of relevant, inter-comparable data over broad areas and over sustained periods of time so as to allow quantification of change within a system for societal decision-making purposes, and to support real-time data products and forecasts for immediate use by stakeholders. The science rationales for Arctic Ocean observations are derived from community-based source materials. Among these are the Implementation Plan for the U.S. Study of Environmental Arctic Change (SEARCH), the Science Plan for the International Study of Arctic Change, the GCOS (Global Climate Observing System) Implementation Plan, the IGOS (Integrated Global Observing Strategy) Cryosphere Theme, reports from the International Conference on Arctic Research Planning, the U.S. National Research Council report "Toward an Integrated Arctic Observing Network", the documents supporting the International Polar Year Project "International Arctic Ocean Observing System" (iAOOS), the workshops and reports underpinning the Sustaining Arctic Observing Networks (SAON) process, and many subregional and national reports on more focused observation requirements.

These planning documents make clear that human societies in the Arctic region and globally benefit from sustained Arctic Ocean observations in a variety of ways. For the global climate system, the Arctic Ocean is a source of freshwater and a sink for heat, and changes in these processes can affect the global ocean circulation and associated heat distribution. The 
Arctic's sea ice cover helps regulate the planet's radiation balance and influences hemispheric weather and precipitation patterns. A warming Arctic Ocean could allow increased release of methane to the atmosphere from the shallow seabed or from coastal regions. In addition to improving understanding and forecasts of the global climate the observations to be described will also be used to:

- support operational forecasting of weather, sea ice, and ocean conditions;

- detect and predict or project climate-driven variability and change in the state of the Arctic Ocean and sea ice and associated feedback processes;

- anticipate resulting long-term impacts to ecosystems and humans;

- detect and project specific ecosystem responses;

- support marine transportation, including tourism, and offshore marine operations;

- $\quad$ support emergency response operations; and

- enable enhanced scientific research.

\section{OBSERVATIONS IN THE ARCTIC OCEAN AND PERIPHERAL SEAS}

In the following sections, specific observing requirements and approaches will be presented. The $4^{\text {th }}$ International Polar Year (IPY), conducted nominally between March 2007 and March 2009, was the "pilot phase" of implementation of an integrated ocean observing network in the Arctic Ocean and surrounding seas. The Arctic Ocean Science Board (AOSB) catalyzed the creation of an integrated Arctic Ocean Observing System (iAOOS) planning document that describes the broad array of ocean observations planned for the IPY. Among these were the initiation of the U.S. Arctic Observing Network (ocean components primarily funded by the National Science Foundation and National Oceanic and Atmospheric Administration), the European Union's DAMOCLES (Developing Arctic Modeling and Observing Capabilities for Long-term Environmental Studies) Project, Canadian activities supported through the academic-based ArcticNet and elements of Environment Canada, and observations conducted by the Russian Federation through Roshydromet and various institutes of the Russian Academy of Sciences. Many of these activities are depicted in Figs. 1a and 1b.

In moving to sustained observations in the Arctic, a key challenge, not found in temperate regions, is to consider the effect of the presence of an ice cover, that - depending on the state of the ice - can serve to enhance or reduce the coupling between ocean and atmosphere on both the basin- and local-scale, and can serve as a unique habitat for both flora and fauna, on design of an ocean observing system. It is likely that some combination of sustained observations, process studies and local observations will be required.

Since much of the societal benefits of an Arctic observing system are derived in close proximity to the coast where circulation patterns and predictability of the ice cover are more challenging, innovative approaches that can help integrate field measurements, remote sensing, modeling and local expertise by stakeholders will be required to a larger extent than in other, temperate ocean regions. An Arctic observing system may blaze the path in exploring effective ways to integrate different observation and modeling streams, e.g. large-scale observations for climate purposes and local-scale observations for predicting coastal erosion, to serve broad science and stakeholder needs.

\subsection{Physical Ocean Observations}

The critical parameters to measure for the ocean are heat and salt content, sea surface temperature, and sea surface height of the Arctic Ocean and surrounding seas. A basin-scale system will employ a mix of shelf, continental slope and deep ocean observatories, drifting buoys, floats and mobile vehicles (Fig. 1). These observational assets will monitor changes in volume, heat and salt fluxes via ocean straits and openings, along the continental slope, and in the central Arctic. In addition, the data collected by ship-based and air-borne expeditions will complement the automated monitoring system capabilities. Combined with systems to observe sea ice and the atmosphere, these systems will provide synoptic year-round observations of key oceanographic, cryospheric and atmospheric processes both through the complementary nature of the platform types and through platform interactions. The development of basin-scale geopositioning and communications should be a priority for the Arctic observational effort. Shelf observatories based on AUVs and bottom-mounted instruments will be employed to monitor shallow shelf regions where sea ice is seasonal. Drifting, ice-based or free platforms (Automated Drifting Stations - ADS) with satellite data links will provide ice, ocean, and atmospheric measurements over the central Arctic basin with permanent or seasonal ice cover. Mobile assets, such as drifters, gliders and AUVs, will provide high-resolution survey data along transects within the entire network, including access to the seasonal ice zone and will also provide observations in the major Arctic Ocean straits. The ADS will build on existing systems and will include meteorological, oceanographic, biological and sea ice sensors. The ADS will also provide navigation data to autonomous 
platforms by relaying their (GPS-derived (Global Positioning System)) position via acoustic data link and acting as a communication relay for data passed to them from passing vehicles or to relay commands and/or data from shore to visiting vehicles. This advanced observing system will be a legacy of IPY and will constitute an important contribution to the multidisciplinary, international Arctic Observing Network envisioned by SEARCH, and recently discussed in the National Academy of Sciences report. Data returned from autonomous instruments and from analysis of physical samples will support studies of ocean processes, facilitate numerical model initialization and validation, and stimulate general interest in Arctic science issues.

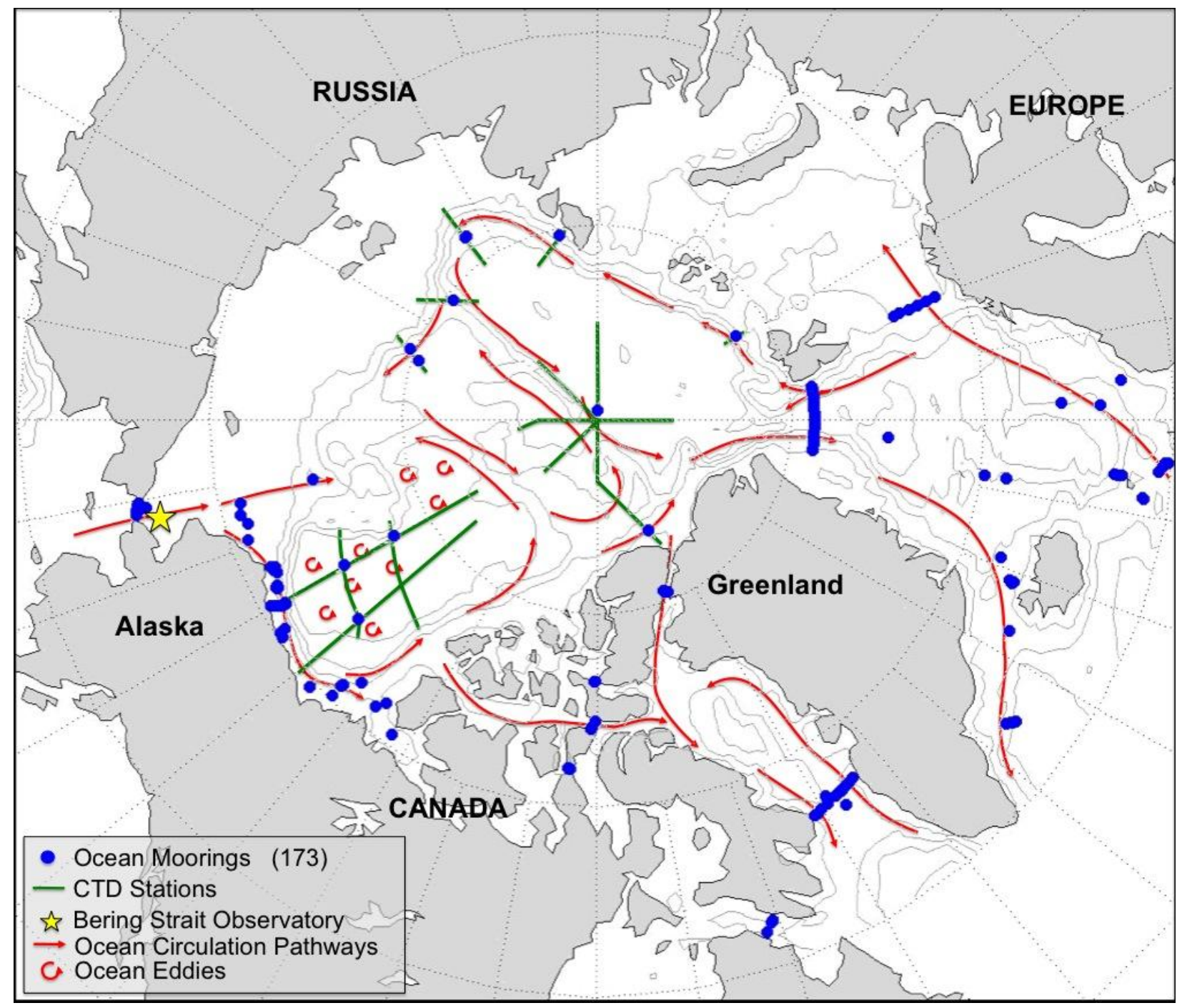

Figure 1a. (above) Map of moorings deployed during the IPY at locations that were determined to be critical through a variety of review and decision processes. Locations of CTD sections conducted in August-September 2008 (green lines) are shown to demonstrate activities associated with ship-based and airborne observations. 


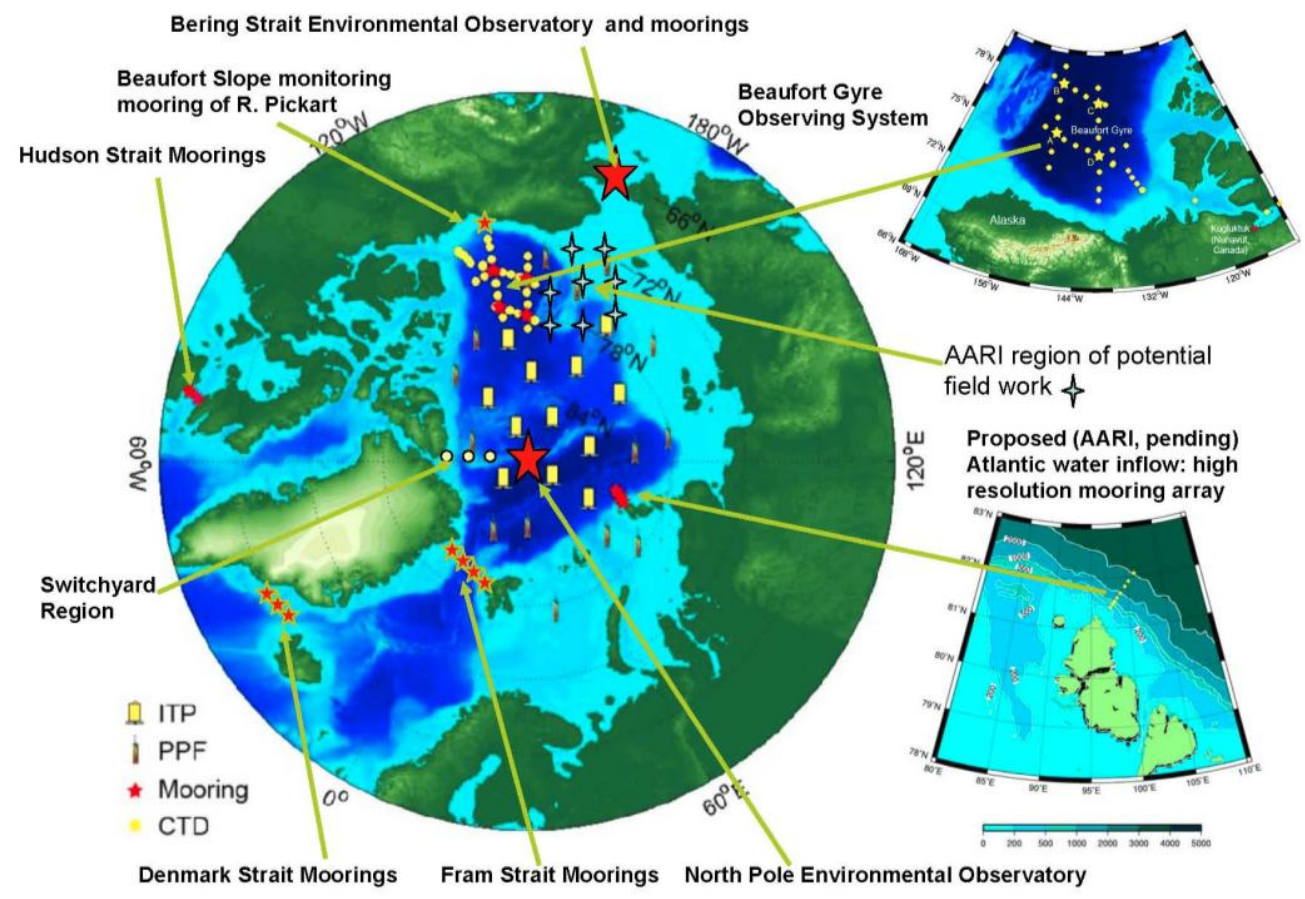

Figure $1 b$ (above) Ice-Tethered Profilers (ITPs) and Polar Profiling Floats (PPFs) are depicted as shown in the legend; their locations are conditional and serve to illustrate a large-scale array of distributed observatories.

\subsection{Biological and Biogeochemical Ocean Observations}

A major goal of the Arctic Ocean biological monitoring network is to observe and predict on seasonal to decadal scales the climate impact on the marine ecosystem of the Arctic Ocean and surrounding shelf seas. Many ocean ecosystem variables are ready for sustained observation (e.g. nutrients, chlorophyll, oxygen, chemical tracers, plankton, benthos - see Fig. 2) while others (e.g. marine mammal populations and productivity) require further research to determine optimal observational approaches.

The strategy of observing needs to be different in ice covered and ice free waters. In the deep Arctic Ocean itself that is mainly ice covered the entire year, observations have to take place from ice stations, icebreakers, satellites and different ice-tethered moorings (Fig. 2). The focus will be on nutrients, phyto- and zooplankton, and the key challenge will be to understand processes and monitor the potential change in the ecosystem as a consequence of climate change.

The shelf seas might need a different observation system. The shelf seas are ice covered during winter (except the southern parts of the Bering and Barents seas that are ice-free year around) and observations methods then might be similar to that outlined for the Arctic Ocean. During summer these areas are easy accessible with research vessels. Both the Bering and Barents Seas have great fish resources, on which process studies in relation to climate will be needed. In addition, the benthic fauna are important in all the shelf seas.

It might be pointed out that an ecosystem approach to management of Arctic seas fisheries and marine mammals is necessary if all of the ecosystem components valued by society are to thrive; since climatic regimes may fundamentally alter relationships within the ecosystem, there is a demonstrable need to develop an understanding of the causal relationships between climate, primary and secondary production, and the population dynamics of upper trophic-level organisms.

Another goal for biological monitoring is to aid in management of living and non-living marine resources so that the benefits of both to society can be realized. Different observing and reporting strategies will be needed to meet this goal, but requirements for data quality, technological advancements, and application of models still apply. Biogeochemical observations employed as tracers of ocean circulation, as regulators of carbon cycle processes, as signatures of shelf-basin exchange and as recorders of change on a broad range 
of time scale - are key to understanding climate-related physical and biological process in the ocean.

Biogeochemical measurements are traditionally obtained by Rosette water-sampling and pumping from ships, aircraft and other platforms. Recent and ongoing developments that allow sampling by electronic sensors, in situ pumps and moored instruments must be included in future observational networks, especially where time-series information is required.

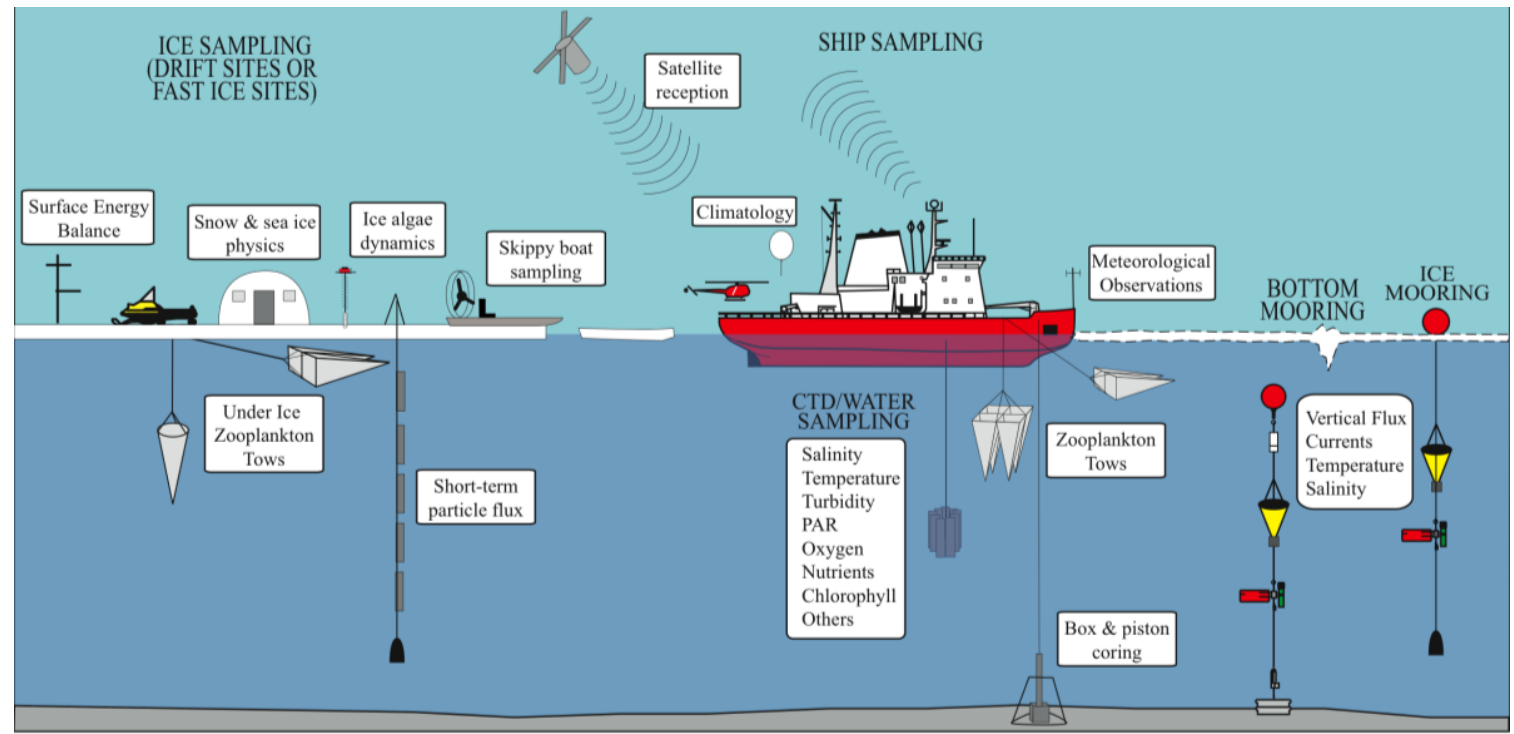

Figure 2: Schematic of the scientific equipment used on the Canadian icebreaker Amundsen and at ice camps nearby.

Biogeochemical measurements have a broad range of application. Understanding the ocean's carbon cycle and biogeochemical cycling will require quality measurements of nutrients $\left(\mathrm{NO}_{3}, \mathrm{NH}_{4}, \mathrm{PO}_{4}\right.$, and $\left.\mathrm{SiO}_{3}\right)$, dissolved and particulate carbon (DOC, POC) dissolved and particulate nitrogen (DON, PON), Carbon and Nitrogen isotopes, parameters controlling the carbonate balance $\left(\mathrm{pH}, \mathrm{pCO}_{2}\right.$, alkalinity), and a suite of rate-limiting trace elements (e.g. Iron, Zinc, Aluminum). Tracers such as oxygen isotope $\left({ }^{18} \mathrm{O}\right)$, Barium (Ba) and alkalinity will yield information on sources and disposition of freshwater inputs. Times scales and pathways of circulation will be obtained from measurements of chlorofluorocarbons (CFCs) and radionuclide tracers including ${ }^{129} \mathrm{I}$ and ${ }^{137} \mathrm{Cs}$. Underway seawater pumping will provide nearcontinuous observations of near surface $(\sim 5 \mathrm{~m})$ water properties important in air-sea exchange, including the gases $\mathrm{O}_{2}, \mathrm{~N}_{2}, \mathrm{CO}_{2}$, and $\mathrm{CH} 4$. Finally, use should be made of new methods in molecular biology to better understand pelagic and benthic microbial processes that drive biogeochemical cycling.

Ancillary measurements providing background to biogeochemical distributions and processes should be added routinely to CTD/Rosette casts (e.g. transmissivity, fluorescence, nitrate, dissolved oxygen and photosynthetically-available radiation).

\subsection{In-situ Sea Ice Observations}

An in-situ sea ice observing network should include the three components of the Arctic sea ice cover; landfast ice, seasonal ice, and perennial ice. Sea ice observations need to be made in an integrated, collaborative fashion with other elements of the ice ocean - atmosphere - biogeochemical system. There should be extensive communication between observationists, modelers, and stakeholders not just to disseminate results, but to work together to design an observational network.

There are three categories of in-situ observation for seasonal sea ice: on-ice and aerial survey campaigns, in-situ sensors on drifting ice with data recorded or relayed via satellite and sub-sea internally recording instruments on moorings. Since all have limitations, an integrated observing system should take advantage of each in its own domain of advantage. There is a unique geographic pattern of vulnerabilities and limitations for each observational approach. Surveys can be constrained by ice thickness, daylight, weather and proximity to shore base. Drifting installations are limited by the same factors, plus the practicality and expense of logistics for installation and maintenance, plus vulnerability to loss via animal damage, ridge building, melting of the ice platform through seasonal change or drift on an ice conveyor or via mutilation of 
the pack by ocean swell; they will not tarry in zones of ice divergence, such as flaw leads and polynyas, but do have the advantage of real-time data relay via satellite. Given the increasing area of open water during summer and seasonal ice, the International Arctic Buoy Programme (IABP), has been testing the viability of readily available Surface Velocity Profilers (SVP) that have long been used in lower latitudes to see how they perform in the Arctic. The SVP buoys monitor surface ocean circulation (ice motion in the Arctic), and are usually equipped with sea surface temperature, and sea level pressure sensors. The IABP is also developing a new air droppable expendable Ice Beacon (AXIB) that may be dropped from aircraft, and is designed to survive through the harsher Arctic conditions of melt and freeze-up in the increasing areas of seasonal ice.

The expense and practicality of logistics similarly affects the viability of moored installations, but sub-sea instruments have the advantage of providing continuous year-round data at fixed locations, albeit not in real time; also, moorings are typically only useful for instruments operating via acoustic or optical under-water remote sensing of sea ice.

The landfast ice zone plays a key role in coastal dynamics and provides a range of important services to Arctic marine ecosystems and human activities. Landfast ice extent in the Arctic is controlled by a combination of bathymetry, ice morphology and surface hydrography and ranges between a few kilometers wide in parts of the North American Arctic to well over one hundred kilometers wide in large stretches of the Siberian Arctic. In this context, in-situ landfast ice observations provide important information on the mass budget and seasonal cycle of landfast ice as well as its stability and dynamics. The former can be obtained from automated or manual sea ice thickness measurements over broad areas, similar to approaches for drifting ice. Since landfast ice dynamics occur on time and spatial scales not always well covered by remote sensing data, coastal radars and automated photography (web cams) have proven to be of value in linking ground-based with satellite observations. Given the importance of landfast ice for marine ecosystems and human activities, communitybased observation programs, have proven to be of great value.

The drifting ice pack consists of seasonal and perennial ice. In recent years there has been a decrease of perennial ice and an increase in seasonal ice, necessitating the development of new observational technologies and strategies to deploy these instruments. Key sea ice cover parameters include ice thickness, snow depth, ice motion, and ice growth and decay. Complicating the observations is the spatial and temporal variability of the sea ice cover and observations need to encompass both spatial surveys and time series. Platforms for the work include: icebreaker cruises, ice camps, autonomous ice tethered instruments measuring ice temperature and mass balance; drifting buoys monitoring ice position, air temperature, and barometric pressure; and ice profiling sonars at the top of moorings that may also contain other instruments. It is critical to coordinate the planning of the observational programs and integrate the results into a standardized, easily accessible database.

Seasonal pack ice has always extended far beyond the Arctic into the western Atlantic and Pacific Oceans. It is now expanding within the Arctic Ocean to replace diminishing multi-year pack ice. Recent change has been less remarkable for Arctic seasonal pack ice than for multi-year ice and models predict that seasonal pack ice will dominate the Arctic Ocean in winter for the foreseeable future. Most Arctic coastal communities abut seasonal, not perennial, sea ice. The presence and characteristics of seasonal ice are critical to the conduct of traditional lifestyles, to marine wildlife management (mammals and birds favour seasonal pack ice), to weather and storm surge forecasting, to navigation in ice, to coastal and offshore engineering and to offshore environment assessment (e.g. hydrocarbon development). The information of most relevance to these applications includes ice presence and drift, thickness distribution, ridging and leads, snow depth and internal temperature; it is required as time series with minimally regional and optimally hemispheric coverage.

In addition to extensive use by Arctic communities or industry, sea ice provides important services to society as a whole. Broadly, such sea-ice system services can be broken down into the following categories: (1) climate regulator, marine hazard, and geological agent or coastal buffer, (2) use of landfast ice as a platform for transportation and installation of structures (e.g. for oil and gas production), (3) cultural benefits derived from the "icescape" by indigenous societies and others, and (4) support of food-webs and biological diversity as an important habitat. The societal benefits of ocean observing systems can be maximized by providing data and information that is directly tied to such different ice uses and services, at the relevant temporal and spatial scales, such as depicted in Fig. 3. This requires communication with different stakeholder groups, e.g. through collaborative efforts, or through processes such as stakeholder forums. For example, the University of Alaska North by 2020 Forum (www.alaska.edu/ipy) and similar efforts indicate an urgent need to calibrate (coastal) ice and ocean models by indigenous experts. 


\subsection{Surface-based Meteorological Observations}

Meteorological observations in the Arctic are collected by stations based on land, and in the Arctic Ocean (Fig. 4). Due to the remoteness of the Arctic, most of these stations are automated to monitor the fundamental parameters of sea level pressure (SLP) and surface air temperature (SAT). However, many stations are manned and monitor a broad range of meteorological parameters, as well as ocean and sea ice parameters.
The International Arctic Buoy Programme (IABP, http://iabp.apl.washington.edu/) has maintained a network of drifting buoys on the Arctic Ocean since 1979, to support research, as well as operational weather and ice forecasting. The IABP has been evolving to better support research and operational requirements by deploying buoy which not only measure SLP and SAT, but also ocean currents, temperatures and salinity. Other buoys have been enhanced to measure ice mass balance using thermistor

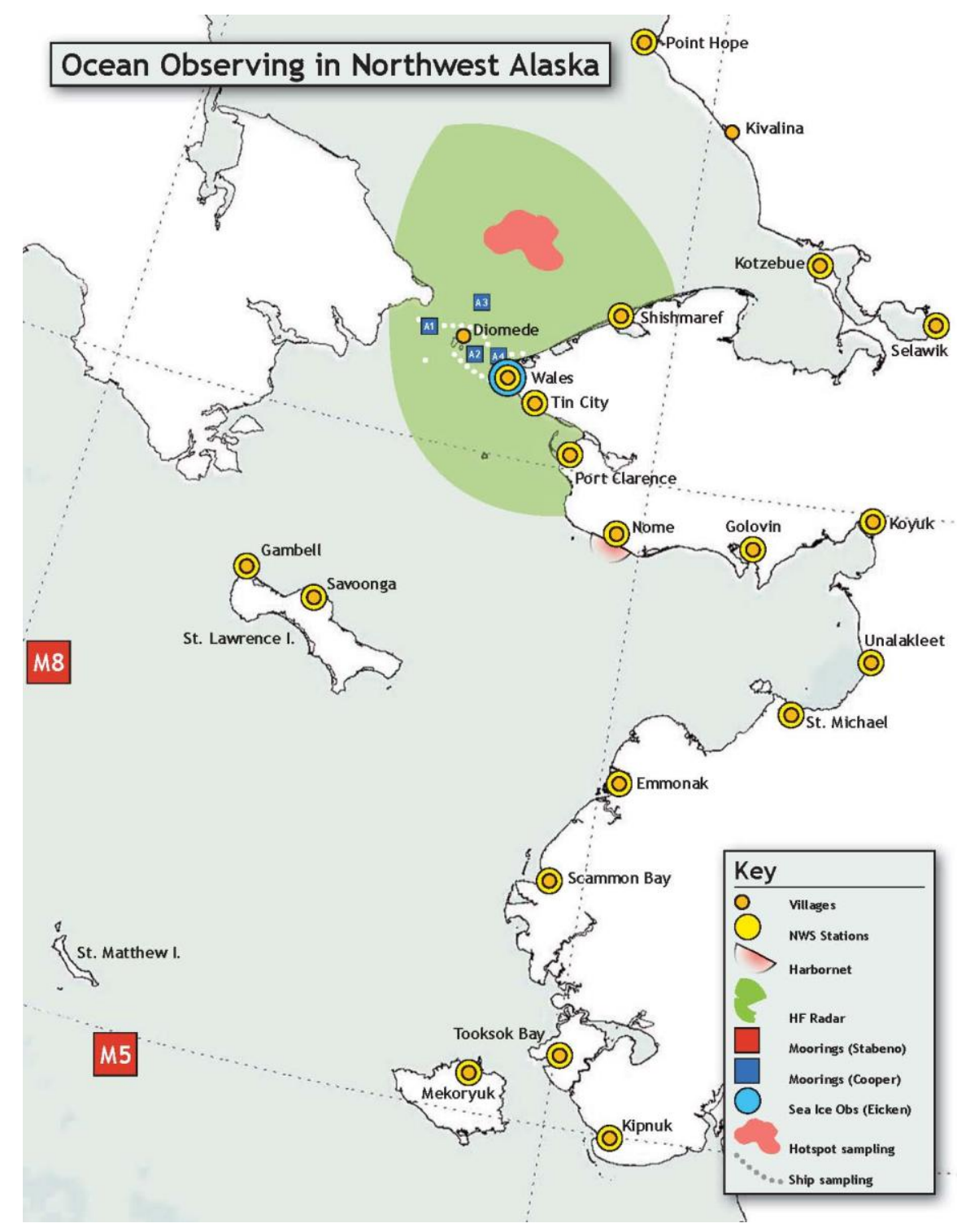

Figure 3: Schematic showing desired coastal ocean observations in the Bering Strait region. 


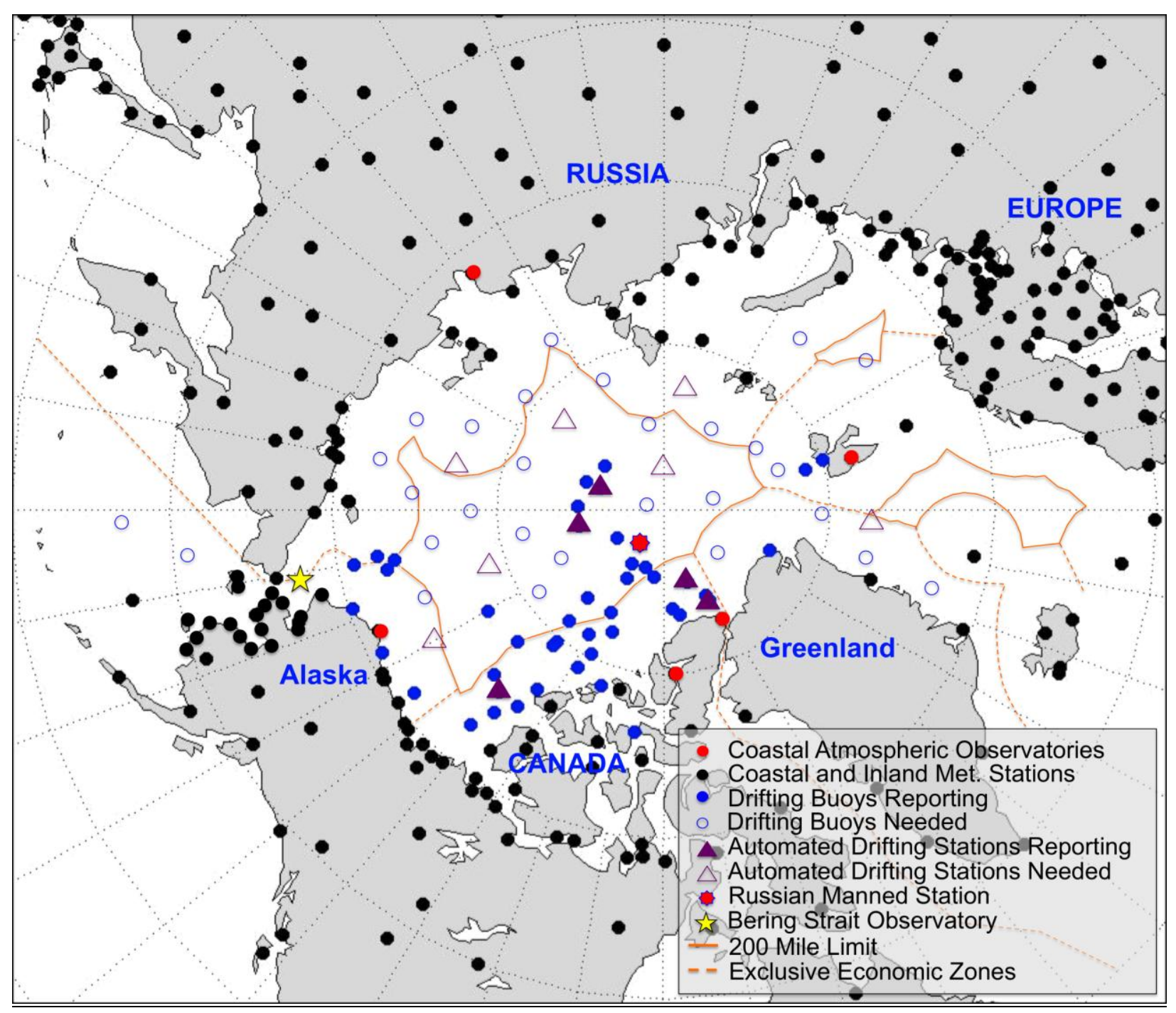

Figure 4: Meteorological Observing Networks for the Arctic.

strings and pingers aimed at the top and bottom of the sea ice. Such stations provide critical atmospheric, ice, and upper ocean hydrographic measurements that cannot be obtained by other means.

Marine observations at coastal stations in the Russian Arctic (the White, Barents, Kara, Laptev, East-Siberian and Chukchi Seas) include: measurements of sea level, water temperature, sea state; measurements of water conductivity, sea ice conditions (concentrations), ice thickness and snow density.

There are 15, 12, 15, 6, 6, and 3 coastal marine stations in the White, Barents, Kara, Laptev, East-Siberian and Chukchi seas, respectively. The meteorological program includes observations of air temperature at 2-m level, atmospheric pressure, wind speed and direction, visibility, air humidity, cloudiness, precipitation, atmospheric phenomena, height and density of snow on ground, and soil temperature with 6-hour intervals.

\subsection{Satellite Observations}

Satellite instruments are essential for delivering sustained, consistent observations of the Arctic Ocean. No all-encompassing sensor exists; rather, the combination of data from different yet complementary sensors is required. The baseline elements of the optimal satellite remote sensing system for a largely ice-covered ocean are a coordinated combination of visible to thermal infrared wavelength imagers and atmospheric sounders, passive microwave radiometers, synthetic aperture radars, laser and radar altimeters, and radar scatterometers. Gravity missions are important for monitoring ice sheets, changes in which impact the ocean in terms of freshwater input and sea level. 
The continued production of unified, consistent time series maps of ice surface temperature and albedo from Advanced Very High Resolution (AVHRR) and Moderate Resolution Imaging Spectroradiometer (MODIS) data is important for monitoring temperature change and its spatial variability. Methods of estimating ice thickness with optical imagers like AVHRR and MODIS need to be further developed and validated. Ocean color is currently measured by MODIS and will continue to be available from the future Visible Infrared Imager Radiometer Sensor (VIIRS) instrument. Hyperspectral infrared sounders provide unprecedented detail of the vertical structure of the Arctic atmosphere, but their information has not been fully exploited for studies of low-level temperature inversions and cloud properties.

Satellite-borne dual-polarized, multi-frequency passive microwave radiometers provide ice concentration/extent, motion, and melt. These data records should continue without interruption. Future acquisitions at a high resolution (optimally $1-3 \mathrm{~km}$ ) are highly desirable. The Advanced Microwave Scanning Radiometer for EOS (AMSR-E) provides more than double the spatial resolution of the Special Sensor Microwave/Imager (SSM/I), additional channels, improved products, and entirely new products such as snow depth over seasonal ice and ice temperature. The NPOESS Conical Scanning Microwave Imager/Sounder (CMIS) has been descoped. Its replacement will be delayed, making overlap with AMSR-E unlikely. Passive microwave sensors on Global Change Observation Mission (GCOM) satellites could fill potential gaps.

Synthetic aperture radar (SAR) instruments provide high-resolution information on sea ice deformation, leads, ridging, and new ice production. Continued wide-swath SAR imagery is critical to operational sea ice analyses and detailed regional ice mapping. SAR missions such as Radarsat-2 (planned) and TerraSAR$\mathrm{X}$ (recently launched) could build valuable time series of cryospheric observations. SAR interferometry (InSAR) is a major missing element in plans for continued cryospheric observation. Flying two companion SAR satellites to provide operational interferometry products of a high quality is an exciting technological advance. The TanDEM-X mission is the first step for a planned constellation of radar satellites. The Global Monitoring for Environment and Security (GMES) Sentinel-1 satellite is planned as a C-band SAR mission with a possible two-satellite constellation.

Spaceborne altimeter data continuity is essential for benchmarks of ice-sheet change and the measurement and monitoring of sea ice thickness. Follow-on radar and laser altimeter missions need to be launched to ensure uninterrupted coverage and enable monitoring of longer-term change. The extraordinary accuracy displayed by ICESat-1 enables regular repeat laser altimetry coverage. The proposed launch of ICESat-2 in 2011 is essential in this respect. The continued launch of further laser missions beyond ICESat-2 is a high priority. The GMES Sentinel-3 radar altimeter will operate with a baseline performance of ENVISAT RA-2 and the high along-track SAR capability of Cryosat-2. Sea level is not measured accurately in the Arctic. Sea surface topography sensors such as Jason-1 and Jason-2 measure only to about 65 degrees of latitude. ICESat-1 is considered to be of only medium accuracy for sea level measurements.

In addition to providing wind velocity measurements over ice-free oceans, satellite radar scatterometer data are increasingly used in operational and research analyses of sea ice and terrestrial snow cover, large iceberg tracking, and studies of ice sheet near-surface characteristics and surface melt/freeze detection. These low-resolution radars complement SAR with their broader swath and more frequent coverage. Improved sea ice motion products are currently obtainable from the merging of motions from radar scatterometry, passive microwave radiometry, and buoys. The SeaWinds instrument and the Advanced Earth Observing Satellite (ADEOS) have provided routine polar Ku-band observations since 1999, and the 2006 launch of MetOp-1 ensures continuity in the C-band time series of Advanced Scatterometer (ASCAT) measurements.

The gravity field measured by the Gravity Recovery and Climate Experiment (GRACE) satellite allows for the determination of ice sheet mass changes and their impact on sea level. Continuing GRACE-type satellite gravity missions is essential. Such missions are required, however, beyond ESA's GOCE to better understand ice-sheet mass loss, with the resulting impact on global sea-level rise.

New sensors and methods are also needed. Spaceborne L-band radiometry shows promise as a means of remotely measuring sea ice thickness. The development of a robust spaceborne technique for observing snow accumulation rate requires the continued collection of passive microwave data at 6-7 GHz. Combining passive microwave with scatterometry may provide further improvements in ice-type discrimination.

While there are some gaps in the satellite observing system over the next decade as a result of satellite failures and budgetary issues, overall, remote sensing of the polar oceans is robust and improving. Many parts of the electromagnetic spectrum are being measured, and ways of combining the diverse information are constantly being developed. New technologies with exciting potential continue to be 
explored. New satellite products developed for IPY, and special satellite acquisitions that took place during IPY as part of the Global Inter-agency IPY Polar Snapshot Year (GIIPSY) project, will be part of its legacy and should be sustained through continued funding and coordination.

\section{DATA ANALYSIS, DATA ASSIMILATION AND MODELING}

It is practically impossible to construct, understand, and explain a "global" picture based on observational data without modeling. On the other hand, it is useless to employ models for this purpose and for prediction of climate change without model validation e.g. determination of model errors and their uncertainties using observations. The data coverage for model validation has to be relatively dense to reproduce four dimensional variability of the system. For the Arctic region where sustained observations are based on coastal stations and where data in the central Arctic are sparse and come from occasional scientific campaigns this condition is difficult to satisfy. On the other hand, considering model validation and model improvement as one international process it is possible to achieve high model accuracy via (i) modeling with data assimilation which provides gridded data sets that are physically consistent and constrained to match available observations and can be used as a first order data for model validation, (ii) model improvement based on the analysis of errors of these gridded data sets and introduction of better model physics and parameterizations.

Accurate gridded atmospheric, cryospheric, and ocean fields from models, consistent with and constrained by point observations, are key to understanding the origin of the observed Arctic change and is essential for forming accurate budgets of numerous climate variables such as heat and freshwater fluxes. An Integrative Data Assimilation for the Arctic System (IDAAS) has been recommended for development by a special interagency research program "A Study of Environmental Arctic Change“(SEARCH, 2005). While existing operational reanalyses assimilate only atmospheric measurements, an IDAAS activity would include non-atmospheric components: sea ice, oceanic, terrestrial geophysical and biogeochemical parameters and human dimensions data. Atmospheric reanalysis products play a major role in the arctic system studies and are used to force sea ice, ocean and terrestrial models, and to analyze the climate system's variability and to explain and understand the interrelationships of the system's components and the causes of their change. Two projects for IDAAS development (to improve atmospheric arctic reanalysis and to develop reanalysis procedures for sea ice and ocean coupled system) were recently supported financially by NSF. These projects' results will include: tools for arctic reanalysis, and the first order products which will consist of gridded atmospheric, sea ice and oceanic parameters for the past 50 years. Ice-ocean-ecosystem modeling with data assimilation is a next step for IDAAS implementation.

\section{DATA MANAGEMENT AND ARCHIVAL}

Observational data becomes useful when it is easily accessed and broadly available. In the post-IPY period and beyond, data management functions must include software to provide data access and display via the web, procedures for ensuring that project data is actually accessible and available in a suite of formats, and tools for integration of diverse types of data to facilitate recurring and novel types of products. There must be secure means for scientists and managers to enter information describing present and planned research projects, associated meta-data, and instructions for access of the actual data. There must be means for project information and datasets to be archived locally and uploaded to national databases where relevant. The needs of data users must be considered as well. Search tools are required, based on keywords, the meta-data, and other relevant search parameters, as well as tools for data integration, graphical display, and analysis.

There are already several prototypes of modern data management systems. In the US, for example, there is the system being developed by the Alaska Ocean Observing System, the Observing System Monitoring Center developed by NOAA, and the Cooperative Arctic Data and Information System supported by NSF. These useful web-based approaches are intended to facilitate research planning, data analysis, and product preparation. The goal is to ensure that good data becomes useful information now, and remains available for new uses far into the future.

Significant effort is needed to ensure that these various activities are converging around a set of "best practices" so that each can be a functioning "node" in a 
global data management scheme. This is essential if we aspire to a piece together a global ocean observing system from independently implemented components.

\section{ORGANIZATION OF REQUIRED ACTIVITIES}

The observing and related activities described in earlier sections will be carried out by various funding and implementing organizations. There will likely be both quasi-operational activities supported by the service agencies, as well as shorter-term research activities supported by granting agencies. Ideally, all will be guided by a common understanding of what is required and of each agencies area of responsibility. This common understanding can be achieved and updated by frequent consultations and sharing of future plans. The Sustaining Arctic Observing Networks process, organized by the Arctic Council and the International Arctic Science Committee, is one means of achieving this. Others include the newly-formed WMO Executive Council Panel of Experts on Polar Observations, Research and Services, the WMO Space Task Group for IPY, and the WMO Global Cryosphere Watch. However it is done, the responsibility for success lies with agency officials, leaders of observing networks, and chairs of science teams who must voluntarily work together to define, fund, and implement the required Arctic ocean observing activities.

\section{APPROACHES TO COORDINATED INTERNATIONAL SUPPORT OF PRIORITY ACTIVITIES}

There are five countries that directly border the Arctic Ocean and peripheral seas - Canada, Denmark/Greenland, Norway, Russia and the United States. These countries will have to agree on how in situ ocean observing in their inland and territorial waters and their Exclusive Economic Zones (EEZ) is to be conducted. An initial step should be a consultation among agency officials from these countries to review the proposed observing activities, identify any national concerns, and seek agreement on the next steps. Many other countries have scientific and societal interests in Arctic ocean observations, and these interests should be recognized and accommodated in the practical arrangements.

\section{LEGAL FRAMEWORKS AND EEZ ISSUES}

A nation bordering the ocean has four stages of authority over the adjoining ocean, and a fifth potential stage. A nation has full sovereignty over its "internal waters", defined by straight baselines from points of land. For the adjacent 12 nautical miles, the Territorial Waters, a nation has full sovereignty over resources and the right to enforce laws, but must allow innocent passage (submarines must surfaced to be considered "innocent"). For an additional 12 nautical miles, the Contiguous Zone, a coastal state has jurisdiction over foreign ships and may enforce laws. For a total distance of 200 nautical miles from the territorial sea baselines, the Exclusive Economic Zone, a nation has full rights for exploring, exploiting, managing, and conserving living and non-living resources of the water, seabed and subsoil, and may require foreign ships to conform to international standards, but no other rights. Under the U.N. Convention on the Law of the Sea (UNCLOS), a nation may petition for an Extended Continental Shelf, which would carry full rights for exploring and exploiting resources on or in the seabed and subsoil, but no other rights.

There are substantial difficulties in the development of a pan-arctic observational network associated with legal frameworks for Exclusive Economic Zone (EEZ) issues. Increasingly rapid physical changes in the Arctic have led to a resurgence of interest in jurisdictional issues relating to who controls what. In these circumstances while the Arctic is not plagued by unresolved territorial disputes, there are problems related to the legality of observations in the EEZs and data availability from these regions in real time. Admitting that the impact of Arctic warming is associated not only with significant environmental change but also with increased Arctic accessibility during the entire year, it becomes clear that the national Arctic EEZ regulations have to be reconsidered and improved, especially for environmental observation and transboundary issues. Some of these recent developments with a particular focus upon outer continental shelf claims to the Arctic Ocean, navigational rights and freedoms within the Northeast and Northwest Passages, and the development of the Arctic Council have been discussed at the International Symposium "Looking Beyond the International Polar Year: Emerging and Re-emerging issues in international law and policy for the Polar Regions", held at the University of Akureyri, Iceland, 7-10 September 2008. The papers of this symposium have analyzed the legal frameworks of recent developments and discussed recommendations for the development of an Arctic Treaty, borrowing from some of the concepts and principles which have been adopted in Antarctica. However, during a Ministerial meeting in Ilulissat Greenland, 27-29 May 2008, the five nations bordering the Arctic Ocean have agreed that a new treaty is not necessary.

While the debate over the need for a formal Arctic Treaty may not be over, the current stated policies of the Arctic government's means that the existing set of frameworks must be the basis for organizing collaborative observations in the Arctic. The existing frameworks include the UNCLOS (not yet formally 
accepted by the U.S., although the U.S. indicates it is acting as though it had acceded to the convention), non-binding regulations established under the International Maritime Organization, voluntary actions agreed by the Arctic Council, and various bi- and multi-lateral agreements that define voluntary means of meeting mutual objectives. It is this latter type of framework that seems best suited at this time for implementing Arctic-wide ocean observing activities.

\section{NEXT STEPS AND FUTURE DIRECTIONS}

There is much interest in sustaining the enhanced level of Arctic ocean observations that existed during the IPY period of 2007-2009. The results from the IPY will provide new insight on the most cost-effective observing strategies and most reliable of the emerging technologies. A key task in the post-IPY period is to refine the most important science questions and most urgent user needs, and provide an updated observing strategy to meet each. During 2010, the (Arctic) ocean observing community should be challenged to perform this task. The key priorities for sustained observations appear at this time to be:

1. Estimating change in heat and fresh water content of the Arctic Ocean and monitoring the influx of heat and salt from the Atlantic and Pacific;

2. Estimating change in sea ice extent and thickness and observing the factors that control sea ice growth and melt;

3. Observing the seasonal evolution of land fast ice, coastal surface currents and coastal storm surge; and
4. physical and chemical conditions in the ocean, including observing productivity, ecosystem structure, and populations of key species and groups.

These priorities require that existing in situ and satellite observations be continued. However, recent assessments of polar observing networks indicate that new observations must also be initiated. This means filling spatial gaps in current networks, but it also means improving the accuracy with which we measure ocean, ice, and atmosphere properties by adding new sensors and integrating existing systems. Regarding the latter, the value of combining measurements from multiple instruments and using in situ and satellite data with models is becoming increasingly apparent. The Committee on Earth Observation Satellite (CEOS) satellite constellations and the NOAA National Snow Analyses are good examples of combining measurement systems and integrating measurements and models.

The IPY science conference of June 2010 will provide the first in-depth look at the results from the observing systems deployed in the Arctic Ocean during the IPY period. The relevant funding and implementing agencies will have a rare opportunity to review Arcticwide and contemporaneous results. They should capitalize on this chance by amending or developing their plans for sustained observations in the Arctic Ocean, and creating a coordinated implementation approach. Scientific understanding, user needs, logistic complexities, and national policies must all be considered in developing this approach, which will most likely be overseen by a government-based structure. 
Draft Table of Arctic-relevant Technology Readiness Levels

\begin{tabular}{|c|c|c|c|c|c|}
\hline & Operational & Commercial & $\begin{array}{l}\text { Research: } \\
\text { Proven }\end{array}$ & $\begin{array}{l}\text { Research: } \\
\text { Prototype }\end{array}$ & $\begin{array}{l}\text { Proof of } \\
\text { Concept }\end{array}$ \\
\hline \multicolumn{6}{|l|}{ Ocean, physical: } \\
\hline CTD & & $\begin{array}{l}\text { Sensors for } \\
\text { moorings, } \\
\text { drifters, floats, } \\
\text { gliders }\end{array}$ & $\begin{array}{l}\text { Ice- and trawl- } \\
\text { resistant anchors } \\
\text { and winch systems }\end{array}$ & & \\
\hline Currents & & $\begin{array}{l}\text { Sensors for } \\
\text { moorings }\end{array}$ & $\begin{array}{l}\text { Ice-avoiding sensor } \\
\text { deployment }\end{array}$ & & \\
\hline Location & GPS & & & $\begin{array}{l}\text { Acoustic } \\
\text { navigation under } \\
\text { ice }\end{array}$ & \\
\hline Ice extent & $\begin{array}{l}\text { Satellite passive } \\
\text { microwave }\end{array}$ & & Coastal radar & & \\
\hline Ice thickness & $\begin{array}{l}\text { Ice-profiling sonar } \\
\text { on moorings }\end{array}$ & $\begin{array}{l}\text { Ice mass balance } \\
\text { buoys }\end{array}$ & $\begin{array}{l}\text { Electromagnetic } \\
\text { sleds, submarine } \\
\text { sonar }\end{array}$ & $\begin{array}{l}\text { Satellite optical } \\
\text { sensors; laser \& } \\
\text { radar altimeter }\end{array}$ & $\begin{array}{l}\text { Amphibious* } \\
\text { mass balance } \\
\text { buoys }\end{array}$ \\
\hline Ice motion & $\begin{array}{l}\text { Drifting buoys; } \\
\text { satellite passive and } \\
\text { active microwave }\end{array}$ & & & $\begin{array}{l}\text { Satellite optical } \\
\text { sensors, coastal } \\
\text { radar }\end{array}$ & \\
\hline Waves, erosion & $\begin{array}{l}\text { Pressure-gauge } \\
\text { wave recorders }\end{array}$ & $\begin{array}{l}\text { Coastal camera } \\
\text { systems }\end{array}$ & & & \\
\hline Sea level & Tide gauges & $\begin{array}{l}\text { Bottom pressure } \\
\text { recorders }\end{array}$ & Satellite altimeters & & \\
\hline $\begin{array}{l}\text { Surface } \\
\text { temperature, }\end{array}$ & $\begin{array}{l}\text { Satellite optical } \\
\text { sensors, drifting } \\
\text { buoys }\end{array}$ & & & & \\
\hline Albedo & $\begin{array}{l}\text { Satellite optical } \\
\text { sensors }\end{array}$ & & & & \\
\hline $\begin{array}{l}\text { Ocean: chemical, } \\
\text { biological: }\end{array}$ & & $\begin{array}{l}\text { Bio-optical (e.g. } \\
\text { chlorophyll) and } \\
\text { chemical (e.g. } \\
\text { oxygen, } \\
\text { nutrients) } \\
\text { sensors on } \\
\text { moorings }\end{array}$ & $\begin{array}{l}\text { Zooplankton } \\
\text { counters, passive } \\
\text { acoustics }\end{array}$ & RFID tags & \\
\hline \multicolumn{6}{|l|}{ Atmosphere: } \\
\hline Air pressure & $\begin{array}{l}\text { Sensors on drifting } \\
\text { buoys }\end{array}$ & & & & \\
\hline Winds & $\begin{array}{l}\text { Satellite } \\
\text { scatterometers, } \\
\text { drifting buoys } \\
\text { (surface); satellite } \\
\text { optical sensors, } \\
\text { radiosondes } \\
\text { (tropospheric) }\end{array}$ & & $\begin{array}{l}\text { Satellite optical } \\
\text { sensors }\end{array}$ & & $\begin{array}{l}\text { Satellite wind } \\
\text { LIDAR }\end{array}$ \\
\hline Cloud cover & Satellite imagers & & $\begin{array}{l}\text { Non-operational } \\
\text { satellite imagers }\end{array}$ & & \\
\hline $\begin{array}{l}\text { Temperature, } \\
\text { humidity profiles }\end{array}$ & $\begin{array}{l}\text { Satellite sounders, } \\
\text { drifting buoys } \\
\text { (surface); } \\
\text { radiosondes }\end{array}$ & & & & \\
\hline Chemistry & $\begin{array}{l}\text { Satellite sounders, } \\
\text { ozone sensors }\end{array}$ & & & $\begin{array}{l}\text { Air chemistry } \\
\text { sensor packages }\end{array}$ & \\
\hline
\end{tabular}

*Amphibious buoys can be deployed in open water or on sea ice, and can survive a change to the other environment 